\title{
ПОЛНОСВЯЗНАЯ НЕЙРОННАЯ РЕГРЕССИОННАЯ СЕТЬ ИНГИБИТОРОВ КИНАЗ, РЕГУЛИРУЮЩИХ СНИЖЕНИЕ LPS-ИНТОКСИКАЦИИ
}

\section{М.А. Перфильев ${ }^{1}$, П.М. Васильев ${ }^{2,1}$, Д.А. Бабков ${ }^{2,1}$, А.Н. Кочетков ${ }^{2}$,} А.Р. Королева'

${ }^{1}$ Кафедра фармакологии и биоинформатики, ФГБОУ ВО ВолгГМУ Минздрава России, 400001, Россия, г. Волгоград, ул. Ким, д. 20.

${ }^{2}$ Научный центр инновационных лекарственных средств, ФГБОУ ВО ВолгГМУ Минздрава России, 400087, Россия, г. Волгоград, ул. Новороссийская, 39.

DOI: 10.19163/MedChemRussia2021-2021-181

E-mail:maxim.firu@yandex.com

Построение полносвязной нейронной регрессионной сети ингибиторов киназ с асимметричной матрицей связности и оценка ее применимости для прогноза химических соединений на способность снижать LPS-интоксикацию.

Обучающая выборка для построения сети была получена по данным докинга 5328 известных соединений с высокой ингибирующей активностью в специфические сайты сигнальных киназ BTK, IRAK1, JAK1, JAK3 и TYK2, влияющих на уровень LPS-интоксикации. Тестовая выборка была сформирована по данным докинга в эти же киназы 12887 известных соединений, испытанных на способность снижать LPS-интоксикацию. Оптимизацию 3D-моделей лигандов выполняли методами молекулярной механики и квантовой химии в программах Marvin 20.19 и MOPAC2016. Валидные 3D-модели киназ были найдены в базах данных UniProtKB и PDBe, коды 40TF, 6BFN, 6HZU, 7C3N и 3NZ0 для BTK, IRAK1, JAK1, JAK3 и TYK2, соответственно. Ансамблевый докинг в сайты связывания выполняли в программе AutoDock Vina 1.1.2. B качестве метрик связности использовали полученные в программе Weka 3.8.4 коэффициенты нейросетевой регрессии. Рассчитаны значения суммативного и мультипликативного функционалов сети, определены адаптивные границы классификации для выраженной LPS-ингибирующей активности.

Границы классификации выраженной LPS-ингибирующей активности равны 32.20 и 42.70 для суммативного и мультипликативного функционалов, соответственно. Общая точность прогноза на тестовой выборке составила $61.1 \%$.

Построена полносвязная нейронная регрессионная сеть ингибиторов киназ, влияющих на уровень LPS-интоксикации, оценена ее прогностическая способность. Модель используется для поиска новых соединений с LPS-ингибирующим действием, потенциальных лекарственных веществ, предотвращающих развитие цитокинового шторма при осложнениях COVIDинфекции.

Работа выполнена при финансовой поддержке Минобрнауки России

(грант № 075-15-20-777).

$$
-181-
$$

